\title{
Call for editorial board nominations
}

Published online: 4 March 2021

(C) World Maritime University 2021

The WMU Journal of Maritime Affairs (JOMA), as an internationally recognized peerreviewed journal, has been recently included in the Emerging Sources Citation Index in the Web of Science as the first step towards a Social Sciences Citation Indexed (SSCI) journal. JOMA is aiming for full SSCI inclusion in the next few years. One of the key evaluating criteria for gaining successful inclusion is a strong team of editorial board members who works together to enhance the JOMA's academic influence, impact, and international presence.

The editorial board is nominated by colleagues or by self-nomination and serves by invitation. Prospective editorial board members should fulfil the following criteria:

- Major discipline and areas of research to fit with JOMA's aims and scope

- Highly experienced in maritime research after obtaining a doctoral or an equivalent degree

- Good academic, industrial, or policy perspectives that would enhance the diversity of the editorial board

If all of the above requirements are met, please email the editor-in-chief with the following documents:

For the nomination of a colleague(s):

- Contact details (email, phone and profile website) of nominee(s)

- A brief statement about nominee(s) for the role

For the self-nomination:

- A fully updated CV

- A brief statement of yourself for the role

I am looking forward to hearing from you by 15 May 2021. An informal enquiry is also welcome.

Prof. Dong-Wook Song

Editor-in-Chief

Web: www.wmu.se/people/dong-wook-song

Email: joma@wmu.se

Publisher's note Springer Nature remains neutral with regard to jurisdictional claims in published maps and institutional affiliations. 